\title{
The Revenue and Expenditure
}

Tre following tables show the ordinary receipts and issues of the exchequer as completely as the remaining Pells, Auditors', and Jems' rolls of the Exchequer of Receipt will permit. There are many

RECEIPTS.

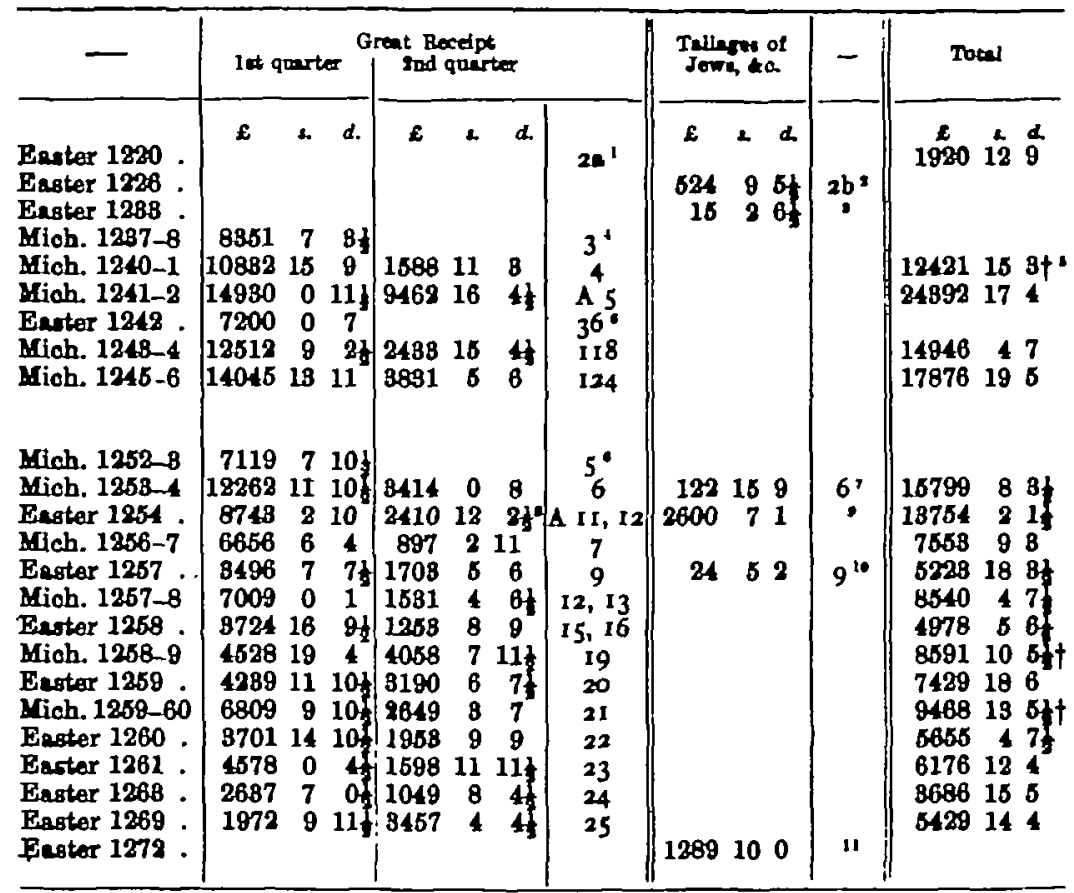

1 This is a headed roll of receipte by connties, the sum of which, on the dorse of m. 1, reads to this eflect:-

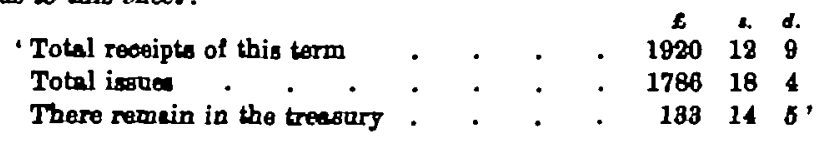

The year mast have begun with an empty treasury.

2 'Rotalns Indeoram de tallegio 4000 mercsirm,' on m. L. The Jewg' Roll (Exch. of Rec.), no. 2, m. 8; is summed 741l. 17s. ifd.

- Jews' Roll (Exch. of Roo.), no. 8.

- Tbis roll rans to 7 Feb. : some membranes misging.

- An obelns distinguishes the 'sums' given in the rolls which are elearly incorrect. Thp errons are very amall.

- Incomplete roll.

' 'Justices of the Jewb.'

- Inclading 70L 11s. 8fd. ' of emercements and fines before the juatices asaigned to the costody, of the Jewr.'

* Tallage of the JowB of 10,000 marks;' also in Jewr' Boll (Exoh. of Rec), no. 6.

10 'Justices of the Jews,' 17l. 11s. 10d.; the like: 'for exchenging without warmat,' 6l. 1B. 4d. This roll records the receipt from Wwiam de Gloncegter of B68L. 18s. 4d., which is not incladed in the 'sum.'

"I 'Tallage of the Jows of 5000 merke' Jewa' Roll (Exch. of Rec.), no. Sa 
of England urder Henry $I I I$.

breaks in the series. The references are to the Pells rolls; but where ' $A$ ' is prefixed, the Auditors' roll is indicated.

ROBBBT JowITT WHITWELL.

Is80R8.

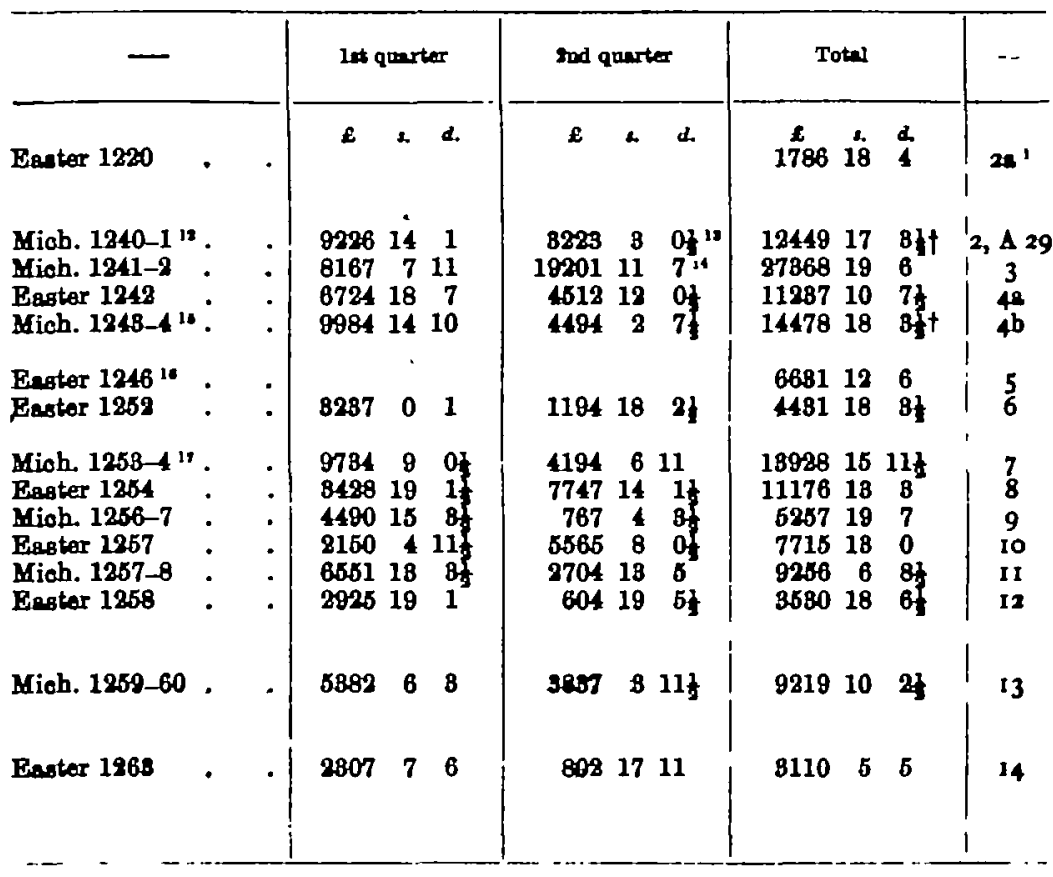

12 The liberate roll of $25 \mathrm{Hen}$. III (28 Oct. 1240-27 Oet. 1241) hes a note on memb. 5 to this effot: ' $\mathrm{Bum}$ of this roll for mits of liberate trom the feant of Bt. Simon and 8t. Jude [28 Oct.] to Baturday, the eve of the Nativity of the B.V.M. [7 Sept.], 18,203l. 1s. Bd.

12 The sum of the dooketed ' $25 \mathrm{Ed} \times \mathbf{r}$. I.'

14 Of this sam 15,301l. 9s. 10d. was psid after 28 March.

16 The ' Pines, liberate, et contrabrevis de Wasconia, 97 Hon. III,' have en entry (' Roles Gascons,' no. 1710), dated sbout 12 March 1243, to this effect: 'Sum by writs of liberate trom the beginning of the year, 2162l. 6v. 6d.; sum by writs of liberate since the king lended in Poiton, to date, $6566 \mathrm{~L}$ 12s. 1d.'

11 Bo docketed ; the roll breaks off five weeks after Trinity, the leat membrane being lost. Down to this point the issues are dated by days; afterwards each quarter is separate, and there are occanional interim totals. Otherwise the items follow with. ont a breat.

v Some membranes missing at the head. 